\title{
Síndrome de Ativação Macrofágica Secundária à Infecção Aguda Pelo Vírus Epstein-Barr
}

\section{Macrophage Activation Syndrome Trigsered by Epstein-Barr Virus}

\author{
Adolpho X. de Carvalho Filho(1), Fabrício de Oliveira Correa ${ }^{(2)}$, Ivan Schumann ${ }^{(3)}$
}

\section{RESUMO}

A síndrome de ativação macrofágica (SAM) ou síndrome hemofagocítica secundária (reativa) consiste de uma rara, grave e potencialmente fatal complicação das doenças reumáticas crônicas, particularmente da artrite idiopática juvenil de início sistêmico, doença de Still do adulto e lúpus eritematoso sistêmico. É caracterizada pela excessiva ativação dos macrófagos, resultando febre, hepatoesplenomegalia, linfadenomegalia, envolvimento neurológico, graus variáveis de citopenias, hiperferritinemia, distúrbio hepático, coagulação intravascular e freqüente falência de múltiplos órgãos. Também ocorre em associação com neoplasias, imunodeficiências e variedade de agentes infecciosos virais (sobretudo do grupo do herpes), bacterianos e fúngicos. Relatamos um caso de SAM decorrente de infecção viral aguda pelo vírus Epstein-Barr tratado com corticóide oral.

Palavras-chave: síndrome de ativação macrofágica, adolescente, hiperferritinemia, Epstein-Barr, citopenia, ciclosporina A.

\section{INTRODUÇÃO}

A síndrome de ativação macrofágica (SAM) ou síndrome hemofagocítica reativa é uma entidade associada com formas familiares e adquiridas. As formas adquiridas podem ser desencadeadas por infecções, neoplasias, imunodeficiências e doenças reumáticas crônicas ${ }^{(1)}$.

Essa desordem foi identificada por Risdall et al.(2), em 1979, e o termo SAM foi descrito pela primeira vez por Hadchovel et al. ${ }^{(3)}$, em 1985, em um relato de sete pacientes com artrite idiopática juvenil (AIJ) de início sistêmico que desenvolveram essa complicação no decorrer da doença. Hoje, a SAM é uma rara e reconhecida complicação da forma sistêmica da $\mathrm{AIJ}^{(4)}$.

Trata-se de um distúrbio decorrente da excessiva ativação e proliferação descontrolada de linfócitos $\mathrm{T}$ e

\begin{abstract}
The macrophage activation syndrome (MAS) or secondary haemophagocytic syndrome (reactive) is an uncommon, severe and life-threatening complication of chronic rheumatic diseases, especially systemic onset juvenile idiopathic arthritis, adult-onset Still disease and systemic lupus eritematosus. It is characterized by the excessive activation of macrophages, resulting in fever, hepatoesplenomegaly, lymphadenopathy, neurological involvement, variable cytopenias, hyperferritinemia, liver disease, intravascular coagulation, often resulting in fatal multiple organ failure. Besides chronic rheumatic diseases, it is also seen in a heterogeneous group of diseases like neoplasms, imunodeficiencies and viruses (especially the herpes group), bacteria and fungi infections. We describe a case report of one patient with MAS triggered by Epstein-Barr virus infection treated with oral corticosteroid.
\end{abstract}

Keywords: macrophage activation syndrome, adolescent, hyperferritinemia, Epstein-Barr, cytopenia, cyclosporine A.

macrófagos, levando à superprodução de citocinas (TNF- $\alpha$, IL-1, IL-6 e interferon $)^{(5)}$.

Ela é clinicamente reconhecida por ocorrer principalmente na forma sistêmica da $\mathrm{AIJ}^{(1,4)}$, e foi demonstrado que a atividade citotóxica da célula natural killer (NK) foi significativamente menor nesses pacientes que nos pacientes com outras formas de $\mathrm{AIJ}^{(6)}$. Tais dados sugerem que essas disfunções citotóxicas e/ou deficiências imunorregulatórias das células NK são anormalidades etiopatogênicas importantes para o desenvolvimento da $\mathrm{SAM}^{(6)}$.

Sua etiologia ainda é pouco clara, entretanto, sabe-se que esse processo pode ser desencadeado por doenças reumáticas crônicas (AIJ, doença de Still do adulto, lúpus eritematoso sistêmico, síndrome de Kawasaki etc.), drogas (antiinflamatórios, metotrexato, sulfassalazina, leflunomida) e infecções (virais, bacterianas e fúngicas) ${ }^{(7)}$.

Recebido em 1/11/2007. Aprovado, após revisão, em 14/3/2008. Declaramos a inexistência de conflitos de interesse.

1. Médico Reumatologista do Hospital de Clínicas de Niterói

2. Médico Hematologista do Hospital de Clínicas de Niterói.

3. Médico-chefe do Serviço de Medicina Interna do Hospital de Clínicas de Niterói.

Endereço para correspondência: Adolpho X. de Carvalho Filho, Rua Coronel Moreira César, 229, sala 1617, 24230-052, Niterói, RJ, Brasil, e-mail: adolphocarvalho@ cremerj.org.br. 
As infecções são os fatores desencadeantes mais referidos $^{(4)}$, sendo mais comumente derivados da família herpesviridae e particularmente decorrente do vírus EpsteinBarr e do parvovírus $\mathrm{B} 19^{(8)}$.

A apresentação clínica é geralmente aguda e dramática. Tipicamente, os pacientes tornam-se agudamente enfermos com febre persistente, hepatoesplenomegalia, linfadenomegalia, alterações neurológicas, graus variáveis de pancitopenia e elevação de enzimas hepáticas ${ }^{(1,7)}$. A hipofibrinogenemia pode conduzir a púrpura e sangramentos ${ }^{(5)}$. O quadro ocasionalmente pode evoluir para a falência de múltiplos órgãos ${ }^{(5,7)}$.

A hiperferritinemia é uma característica laboratorial marcante da SAM. Níveis muito elevados de ferritina são comumente encontrados em doenças caracterizadas por proliferação histiocítica e hemofagocitose ${ }^{(5)} \mathrm{e}$ apresentam correlação direta com a atividade da doença $a^{(5,7)}$.

O diagnóstico é feito pelo mielograma, cuja característica patognomônica é a presença de numerosos macrófagos bem diferenciados fagocitando elementos hematopoiéticos na medula óssea ${ }^{(4,5)}$.

No diagnóstico diferencial, destacam-se a AIJ de início sistêmico e a doença de Still do adulto, nas quais foi demonstrada similaridade de $40 \%$ nos critérios diagnósticos de ambas, até mesmo manifestações clínicas idênticas em pelo menos um subgrupo desses pacientes ${ }^{(9)}$. Outras condições com características clínicas semelhantes incluem infecções virais (citomegalovírus, imunodeficiência adquirida, mononucleose), bacterianas (Salmonella, ricketsia, enterobactérias), parasitoses (leishmaniose), fungos (Aspergillus e cândida) e neoplasias, como os linfomas ${ }^{(7)}$.

O tratamento deve ser iniciado o mais precocemente possível em razão do alto risco de mortalidade, com controle de desordens eletrolíticas (hiponatremia) e desordens de coagulação, bem como o tratamento de infecções intercorrentes quando presentes ${ }^{(4)}$. A estratégia para o tratamento da SAM é feita usualmente com base na administração parenteral de altas doses de corticosteróide (pulsoterapia com metilprednisolona). Atualmente, a segunda droga indicada na literatura é a ciclosporina A, particularmente nos casos refratários aos corticosteróides. Outras modalidades terapêuticas são: imunoglobulina polivalente, ciclofosfamida, plasmaférese e etanercepte ${ }^{(1,5,8)}$.

Nosso objetivo é descrever as características clínicolaboratoriais e terapêuticas em um paciente com infecção aguda viral complicada pela SAM, que apresentou boa evolução com o uso de corticóide oral.

\section{RELATO DE CASO}

Paciente do sexo masculino, 17 anos, natural do Rio de Janeiro e procedente de Niterói, iniciou quadro de odinofagia, poliartalgia e febre baixa cerca de 30 dias antes de sua internação. Procurou atendimento médico quando se suspeitou de angina bacteriana, tendo sido prescritos sucessivamente amoxacilina, ciprofloxacina e sulfametoxazol-trimetoprim sem melhora clínica. Progressivamente a febre aumentou até picos diários de $39^{\circ} \mathrm{C}$, houve piora da prostração, desenvolvimento de linfadenomegalia cervical, palidez cutâneo-mucosa, náusea e anorexia. Foi encaminhado à emergência do Hospital de Clínicas de Niterói, onde foi observada pancitopenia com subseqüente internação.

Ao exame físico, o paciente encontrava-se prostrado, hipocorado $(2+/ 4+)$, hipohidratado $(2+/ 4+)$, febril com $38,8{ }^{\circ} \mathrm{C}$, taquicárdico, com discreta hiperemia da orofaringe, micropoliadenomegalia cervical, axilar e inguinal bilateral e abdome com traube ocupado. Não havia artrite ou rash cutâneo. Apresentava história de traço falcêmico assim como seu irmão gêmeo. Prescritos sintomáticos e hidratação venosa. Iniciada investigação diagnóstica.

O hemograma apresentava pancitopenia com acometimento, sobretudo da série eritróide, permanecendo assim durante todo o período inicial de internação (Tabela 1 ). Glicose, uréia, creatinina e eletrólitos eram normais. A desidrogenase lática (DHL) era de $2.577 \mathrm{U} / \mathrm{L}$ (valor normal até $300 \mathrm{U} / \mathrm{L}$ ). As transaminases (TGO e TGP), a fosfatase alcalina $(\mathrm{FA})$ e a gama glutamil transferase $(\gamma \mathrm{GT})$ permaneceram sempre alteradas durante sua internação (Tabela 1 ). O tempo de atividade de protrombina (TAP) e o tempo de tromboplastina parcial (PTT) eram normais. A avaliação urinária foi normal (elementos anormais de sedimentoscopia, clearence de creatinina e proteinúria de 24 horas). As culturas de sangue e urina foram negativas.

A radiografia de tórax foi normal e o ultra-som de abdome demonstrou hepatoesplenomegalia. A tomografia de tórax demonstrou micropoliadenomegalia mediastinal e as tomografias de abdome e pelve revelaram, além da hepatoesplenomegalia, uma micropoliadenomegalia pélvica.

A velocidade de hemossedimentação (VHS) foi de 40 $\mathrm{mm} /$ hora e o fator antinúcleo (FAN), fator reumatóide (FR), anticorpo anticitoplasma de neutrófilo (ANCA), antiDNA de dupla hélice, anti-Ro, anti-La, anti-Sm, anti-RNP, VDRL, anticoagulante lúpico, anticorpo anticardiolipina IgG e $\operatorname{IgM}$, crioglobulinas, Coombs direto e indireto foram todos negativos. $\mathrm{O}$ complemento era normal. $\mathrm{O}$ ferro sérico, a capacidade de combinação do ferro, ácido fólico 
TABELA 1

ACHAdOS LABORATORIAIS NA ADMISSÃO, DURANTE O PERÍODO DE INTERNAÇÃO E DUAS SEMANAS APÓS A ALTA

\begin{tabular}{|c|c|c|c|c|c|c|c|c|c|}
\hline Exame Data & $\begin{array}{l}\text { 25/5/2007 } \\
\text { Internação }\end{array}$ & $26 / 5 / 2007$ & $27 / 5 / 2007$ & $29 / 5 / 2007$ & $\begin{array}{l}\text { 1/6/2007 } \\
\text { Início do } \\
\text { corticóide }\end{array}$ & $4 / 6 / 2007$ & $6 / 6 / 2007$ & $\begin{array}{c}8 / 6 / 2007 \\
\text { Alta }\end{array}$ & $22 / 6 / 2007$ \\
\hline Hematócrito \% & 24,5 & 22,5 & 21,5 & 19,4 & 16,1 & 17,7 & 22,5 & 22,8 & 31,5 \\
\hline Hemoglobina $\mathrm{g} / \mathrm{dL}$ & 8,0 & 7,2 & 6,9 & 6,3 & 5,0 & 5,3 & 6,5 & 6,6 & 10,4 \\
\hline Leucometria $\left(\mathrm{mil} / \mathrm{mm}^{3}\right)$ & 3,2 & 3,7 & 3,0 & 3,0 & 3,1 & 4,7 & 5,9 & 5,4 & 7,3 \\
\hline Bastões (\%) & 4 & 10 & 7 & 15 & 18 & 4 & 4 & 2 & 2 \\
\hline Neutrófilos (\%) & 23 & 17 & 18 & 31 & 22 & 54 & 69 & 73 & 60 \\
\hline Linfócitos (\%) & 71 & 71 & 67 & 47 & 46 & 40 & 26 & 23 & 27 \\
\hline Plaquetas $\left(\mathrm{mil} / \mathrm{mm}^{3}\right)$ & 108 & 88 & 86 & 102 & 95 & 166 & 196 & 164 & 237 \\
\hline Fosfatase alcalina (U/L) & - & 292 & 51 & - & 235 & 263 & - & 254 & - \\
\hline$\gamma \mathrm{GT}(\mathrm{U} / \mathrm{L})$ & - & 450 & 431 & 425 & 426 & 554 & - & 568 & - \\
\hline TG0 (U/L) & - & 254 & 263 & 253 & 216 & 185 & - & 109 & - \\
\hline TGP (U/L) & - & 75 & 75 & 81 & 70 & 167 & - & 176 & - \\
\hline
\end{tabular}

sérico, vitamina $B_{12}$ sérica e atividade glicose 6 fosfato desidrogenase eram normais. A eletroforese de hemoglobina revelou traço falcêmico com $\mathrm{HbAl}$ de $60,6 \%, \mathrm{HbA} 2$ de $5,1 \%$ e Hbfetal de $0,1 \%$.

A ferritina foi de $29.200,2 \mathrm{ng} / \mathrm{mL}$ (20 até $336 \mathrm{ng} / \mathrm{mL}$ ). O fibrinogênio foi de $179 \mathrm{mg} / \mathrm{dL}(180$ a $350 \mathrm{mg} / \mathrm{dL})$, colesterol de $108 \mathrm{mg} / \mathrm{dL}$ (inferior a 200), triglicerídios de $221 \mathrm{mg} / \mathrm{dL}$ (até $200 \mathrm{mg} / \mathrm{dL}$ ). As sorologias para hepatites A, B e C, toxoplasmose, citomegalovírus, parvovírus B19, HIV I e II foram negativas. A sorologia pelo ensaio imunoenzimático para o vírus Epstein-Barr foi IgM positiva de 160.00 $\mathrm{UI} / \mathrm{mL}$ (reativo $>40 \mathrm{UI} / \mathrm{mL}$ ). Foi realizada uma biópsia de medula óssea que revelou a hemofagocitose (Figura 1).

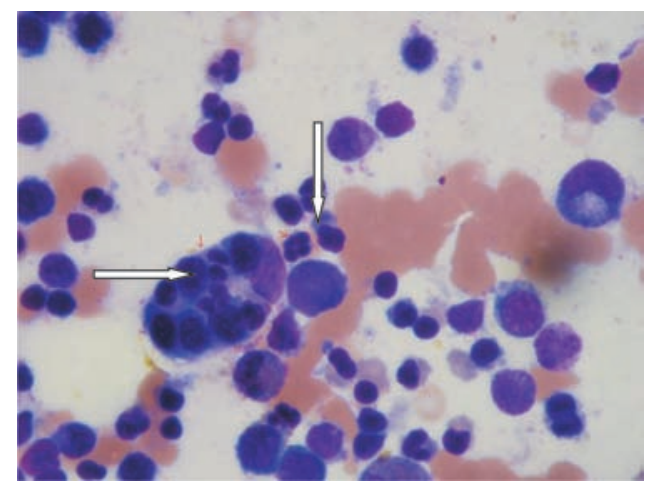

Figura 1 - Histiócito fagocitando 11 formas jovens de eritroblastos, alguns picnóticos e outros ortocromáticos. Nota-se o núcleo do histiócito desviado excentricamente, algo eosinofílico e com alguns grânulos em seu interior (seta horizontal). Demarcado ao lado do histiócito, nota-se eritroblasto com quatro núcleos, exemplificando a intensa deseritropoiese (seta vertical).
Identificada a infecção aguda pelo vírus Epstein-Barr (mononucleose infecciosa) e a SAM secundária, iniciou-se o tratamento.

O paciente, a despeito da febre, da pancitopenia e da prostração, apresentava-se estável, e optou-se pelo uso de prednisona $1 \mathrm{mg} / \mathrm{kg} /$ dia sob estreita vigília. A resposta foi dramática com melhora da febre em torno de 72 horas, com reversão dos sintomas constitucionais e melhora progressiva da pancitopenia (Tabela 1 ).

A nova ferritina sérica oito dias após o início do corticóide já era de 3.221,3 ng/Ml; a linfadenomegalia cervical e axilar deixou de ser clinicamente evidente em torno de 20 dias.

Apresentou como intercorrência clínica somente hidroadenite axilar bilateral no fim de sua internação, que foi tratada com cefalexina por 14 dias.

O paciente foi submetido à redução progressiva e completa da prednisona sem intercorrências e sem a necessidade de outras drogas.

O hemograma e a ferritina normalizaram-se por completo.

Nos seis meses de evolução ambulatorial não houve recorrências de sintomas ou desenvolvimento de qualquer outra doença.

\section{DISCUSSÃO}

Descrevemos o caso de um paciente que desenvolveu SAM decorrente de uma infecção pelo vírus Epstein-Barr (mononucleose infecciosa). 
Apesar de os dados da literatura demonstrarem que nem sempre são encontrados fatores desencadeantes para o início da SAM, as infecções ${ }^{(4)}$ e a $\mathrm{AIJ}^{(1,10)}$ são os fatores desencadeantes mais referidos.

Diversas vezes, apesar de as culturas e sorologias negativas, não se pode descartar a etiologia infecciosa da $S A M^{(4)}$. Durante o estudo inicial para o esclarecimento diagnóstico do quadro clínico em questão, identificou-se o vírus Epstein-Barr.

O paciente apresentava quadro grave e potencialmente fatal decorrente da mononucleose infecciosa - a SAM. Suas manifestações clínicas são explicadas pela ativação macrofágica com liberação de proteases que ativam plasminogênio, levando à formação de plasmina com degradação da fibrina, desencadeando a fibrinólise e a coagulação intravascular disseminada (CIVD). A hiperprodução de citocinas, particularmente a interleucina 1 , o fator de necrose tumoral e a gama-interferon, pode ser a responsável por complicações graves $^{(1,10)}$.

A dificuldade diagnóstica da SAM na mononucleose tem relação com sintomas e sinais, tais como febre, linfadenomegalia e hepatoesplenomegalia.

A evolução clínica clássica da mononucleose nesse paciente foi interrompida pelo desenvolvimento de pancitopenia que conduziu a estudo ainda mais profundo do caso, no qual a hiperferritinemia e a hemofagocitose evidenciadas na biópsia de medula óssea foram decisivas para o diagnóstico.

Este paciente apresentava a SAM, entretanto em nenhum momento apresentou seus principais fatores de mau prognóstico, como alterações neurológicas, distúrbio renal, falência hepática ou diátese hemorrágica ${ }^{(1,7,11)}$. Da mesma forma, não desenvolveu instabilidade clínica como choque e nem mesmo mimetizou sepse ${ }^{(5)}$.

A VHS, apesar da inflamação sistêmica, não se elevou significativamente em virtude da hipofibrinogenemia ${ }^{(7)}$.

A hiperferritinemia, sinal clássico da entidade, caracteristicamente acompanhou a atividade de doença ${ }^{(10)} \mathrm{com}$ significativa queda oito dias após o início do tratamento. Posteriormente normalizou.

\section{REFERÊNCIAS}

1. Silva CAA, Silva CHM, Robazzi TCMV, et al.: Síndrome de ativação macrofágica associada com artrite idiopática juvenil sistêmica. J Pediatr (Rio J) 80(6): 517-22, 2004.

2. Risdall RJ, McKenna RW, Nesbit ME, et al.: Virus-associated hemophagocytic syndrome: a benign histiocytic proliferation distinct from malignant histiocytosis. Cancer 44: 993-1002, 1979.
Em diversas séries de estudo, a hiperferritinemia superior a $1.000 \mu \mathrm{g} / \mathrm{L}$ e a elevação da lactato desidrogenase superior a $1.000 \mathrm{UI} / \mathrm{L}$ (conforme este caso) foram observadas em $90 \%$ e $89,7 \%$ dos pacientes, respectivamente ${ }^{(8)}$.

As alterações clínico-laboratoriais de maior sensibilidade e especificidade encontradas nos critérios da SAM propostas por Ravelli et al. ${ }^{(12)}$ para a forma sistêmica da AIJ foram: plaquetopenia $\leq 262.000 / \mathrm{mm}^{3}$, leucometria $\leq 4.000 / \mathrm{mm}^{3}$, fibrinogênio $\leq 2,5 \mathrm{~g} / \mathrm{dL}$, elevação de enzimas hepáticas, ferritina sérica $\geq 10.000 \mu \mathrm{g} / \mathrm{L}$, triglicerídios $\geq 1,6 \mathrm{~g} / \mathrm{L}$, biópsia de medula óssea demonstrando hemofagocitose, hepatomegalia e esplenomegalia. Este paciente, a despeito da etiologia diferente, apresentou todas essas anormalidades clínicas e laboratoriais, com a exceção de ter uma hipofibrinogenemia bem mais discreta e não apresentar hipertrigliceridemia significativa.

A presença do traço falcêmico aparentemente não influenciou na evolução da doença. Não foram encontrados dados relevantes na literatura quanto à associação de SAM em paciente com traço falcêmico.

Em razão da heterogeneidade etiológica, clínica e evolutiva, o tratamento ainda é individualizado ${ }^{(7)}$.

Neste caso, optou-se pela corticoterapia oral e não pela pulsoterapia com metilprednisolona ${ }^{(10)}$ em razão da estabilidade clínica e da ausência de fatores de mau prognóstico. O uso da corticoterapia oral é citado na literatura ${ }^{(13)}$.

O paciente apresentou resposta adequada com a corticoterapia e não necessitou do uso de droga de segunda linha, como a ciclosporina ${ }^{(1,4,5,8,10)}$.

\section{CONCLUSÃO}

Assim sendo, a SAM deve sempre participar do diagnóstico diferencial de todo o paciente com febre persistente, síndrome adenomegálica e pancitopenia.

A procura da etiologia deve ser ampla e exaustiva para melhor compreensão da entidade e de suas complicações, bem como para a instituição da terapêutica apropriada com a finalidade de reduzir seu potencial de letalidade.

3. Hadchovel M, Prieur AM, Griscelli C.: Acute hemorrhagic, hepatic, and neurologic manifestations in juvenile rheumatoid arthritis: possible relationship to drugs or infection. J Pediat 106 : 561-6, 1985.

4. Prado R, Terreri MTRA, Len CA, Braga J, Hilário MOE: Síndrome de ativação macrofágica em pacientes com artrite idiopática juvenil. Rev Bras Reumatol 44(5): 378-82, 2004. 
5. Ravelli A: Macrophage activation syndrome. Cur Opin Rheumatol 14(5): 548-52, 2002.

6. Villanueva J, Lee S, Gianninni EH, et al.: Natural killer cell dysfunction is a distinguishing feature of systemic onset juvenile rheumatoid arthritis and macrophage activation syndrome. Arthritis Res Ther 7: R30-7, 2005.

7. Emmenegger U, Schaer DF, Neftel KA: Haemophagocytic syndromes in adults: current concepts and challenges ahead. Swiss Med Wkly 135: 299-314, 2005.

8. Ramanan AV, Schneider R: Macrophage Activation Syndrome - What's in a name! J Rheumatol 30: 12, 2003.

9. Emmenegger U, Reimers A, Frey U, et al.: Reactive macrophage activation syndrome: a simple screening strategy and it's potential in early treatment initiation. Swiss Med Wkly 132: 230-6, 2002.
10. Rosa DJF, Nogueira CM, Bonfante HL, et al.: Síndrome de ativação macrofágica após o uso de Leflunomida em paciente com doença de Still do adulto: Relato de caso. Rev Bras Reumatol 47(3): 219-22, 2007.

11. Izzedine H, Brocheriou I, Martinez V, Camous L, Guillemont MC, Deray G: Fever, nephrotic syndrome, and rapidly progressive renal failure. Kidney Int 72: 651-6, 2007.

12. Ravelli A, Magni-Manzoni S, Pistorio A, et al.: Preliminary diagnostic guidelines for macrophage activation syndrome complicating systemic juvenile idiopathic arthritis. J Pediatr 146:598-604, 2005.

13. Lou YJ, Jin J, Mai WY.: Ankylosing spondilitis presenting with macrophage activation syndrome. Clin Rheumatol 26:1929-30, 2007 